\title{
Formation dynamics of subsurface hydrocarbon intrusions following the Deepwater Horizon blowout
}

\author{
Scott A. Socolofsky, ${ }^{1}$ E. Eric Adams, ${ }^{2}$ and Christopher R. Sherwood ${ }^{3}$ \\ Received 16 February 2011; revised 1 April 2011; accepted 4 April 2011; published 12 May 2011.
}

[1] Hydrocarbons released following the Deepwater Horizon (DH) blowout were found in deep, subsurface horizontal intrusions, yet there has been little discussion about how these intrusions formed. We have combined measured (or estimated) observations from the DH release with empirical relationships developed from previous lab experiments to identify the mechanisms responsible for intrusion formation and to characterize the $\mathrm{DH}$ plume. Results indicate that the intrusions originate from a stratification-dominated multiphase plume characterized by multiple subsurface intrusions containing dissolved gas and oil along with small droplets of liquid oil. Unlike earlier lab measurements, where the potential density in ambient water decreased linearly with elevation, at the DH site it varied quadratically. We have modified our method for estimating intrusion elevation under these conditions and the resulting estimates agree with observations that the majority of the hydrocarbons were found between 800 and $1200 \mathrm{~m}$. Citation: Socolofsky, S. A., E. E. Adams, and C. R. Sherwood (2011), Formation dynamics of subsurface hydrocarbon intrusions following the Deepwater Horizon blowout, Geophys. Res. Lett., 38, L09602, doi:10.1029/ $2011 \mathrm{GL} 047174$.

\section{Introduction}

[2] Hydrocarbons released following the recent Deepwater Horizon (DH) blowout were found in deep horizontal intrusions between 800 and $1200 \mathrm{~m}$ [Camilli et al., 2010; Kessler et al., 2011; Valentine et al., 2010], but their formation has not been formally discussed. Here, we adapt empirical relationships determined from earlier lab experiments on buoyant multiphase plumes to identify mechanisms responsible for intrusion formation and provide quantitative estimates of height, dimensions, and initial flow rate.

[3] A buoyant plume entrains ambient fluid (e.g., seawater), and in a stratified fluid it will rise until its (increasing) density matches ambient conditions. Multiphase plumes differ from single-phase plumes (e.g., wastewater plumes) in that the gas bubbles and larger oil droplets that are the source of buoyancy can separate from the entrained seawater plume as it becomes trapped by stratification or deflected by ambient currents (Figures 1a-1c). Literature suggests oil from the DH spill was rapidly atomized at the well head, producing fine droplets, many with diameters below 300 microns [Masutani

\footnotetext{
${ }^{1}$ Zachry Department of Civil Engineering, Texas A\&M University, College Station, Texas, USA.

${ }^{2}$ Ralph M. Parsons Laboratory, Massachusetts Institute of Technology, Cambridge, Massachusetts, USA.

${ }^{3}$ U.S. Geological Survey, Woods Hole, Massachusetts, USA.

Copyright 2011 by the American Geophysical Union. 0094-8276/11/2011GL047174
}

and Adams, 2000], implying rise velocities of less an $6 \mathrm{~mm} / \mathrm{s}$ [Clift et al., 1978]. Moreover, use of subsurface dispersants may have reduced diameters by an order of magnitude causing a two order of magnitude decrease in the droplet rise velocity [National Research Council, 2005]. These very small oil droplets, along with dissolved oil and gas and entrained seawater combined to form the intrusions observed near the DH site.

[4] The behavior of multiphase plumes depends on the relative importance of horizontal currents and stratification (Figures 1a to 1c) [Socolofsky and Adams, 2002, 2005]. When horizontal currents dominate, the bubbles and large droplets exit at a separation height $h_{S}$, leaving a wake of entrained seawater with dissolved and finely dispersed hydrocarbons. When stratification dominates, the plume reaches a peel height $h_{P}$, where dispersed phase buoyancy can no longer lift the entrained seawater; an outer downdraught plume of dissolved and finely dispersed hydrocarbons and seawater is created that eventually traps at a level of neutral buoyancy, $h_{T}$. Laboratory experiments suggest that the plume is dominated by horizontal currents if $h_{S}<h_{P}$ and by stratification if $h_{S}>h_{P}$ [Socolofsky and Adams, 2002]. The main effect of weak currents on stratification dominated plumes is to carry the intrusions downstream.

\section{Methods}

[5] Empirical relationships characterizing buoyant plumes have been developed from laboratory experiments with air bubbles, glass beads (creating inverted, downward falling plumes), crude oil, and buoyant continuous-phase tracers in stratified and flowing conditions [Akar and Jirka, 1995; Socolofsky and Adams, 2002, 2003, 2005]. The experiments indicate that plume characteristics (Table 1) are governed by five parameters: horizontal velocity $U$, ambient density gradient, given by the buoyancy frequency $N=\sqrt{-g / \rho_{r}\left(\partial \rho_{a} / \partial z\right)}$, oil/gas bubble rise velocity $u_{s}$, source buoyancy flux $B_{0}=Q_{0}\left(\rho_{a}-\rho_{0}\right) / \rho_{r}$, and height $z$ above the discharge, where $g$ is gravitational acceleration, $\rho_{r}$ and $\rho_{a}(z)$ are reference and ambient seawater densities, and $\rho_{0}$ and $Q_{0}$ are the density and volume flow rate of the initial oil/gas mixture. Typical parameter values for the DH release [Lehr et al., 2010] and for DeepSpill, a field experiment conducted in 2000 off Norway [Johansen et al., 2003], are listed in Table 2. Many of the parameters for the DH release are still uncertain, and we acknowledge the effect this may have on calculations.

\subsection{Initial Conditions}

[6] Oil and gas were released at the start of the spill from two leaks separated by about $250 \mathrm{~m}$. The spreading ratio (half-width:height) of multiphase plumes is about 1:10, so 


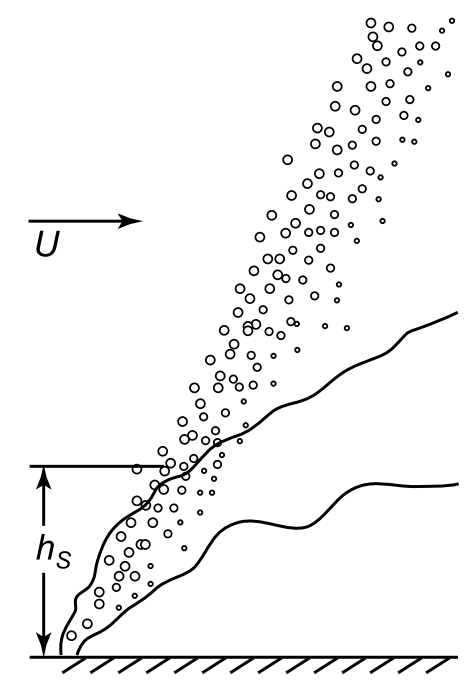

a.) Pure Current

\section{Elevation View}

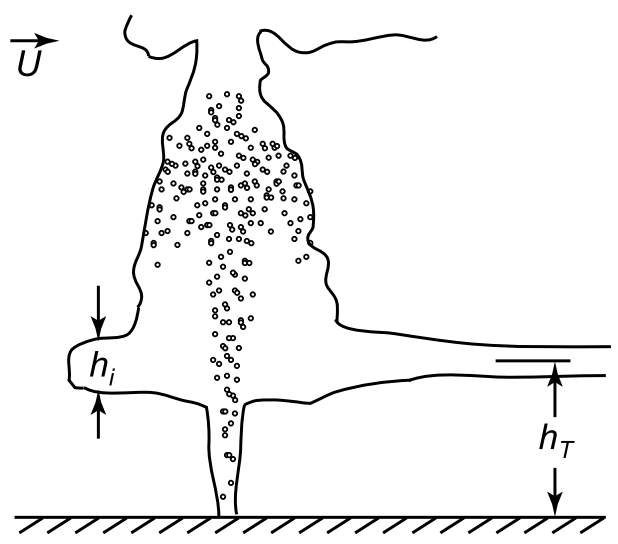

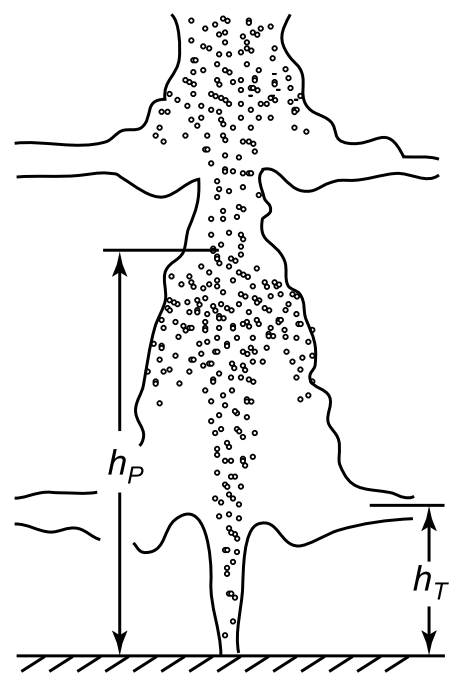

b.) Pure Stratification
Plan View

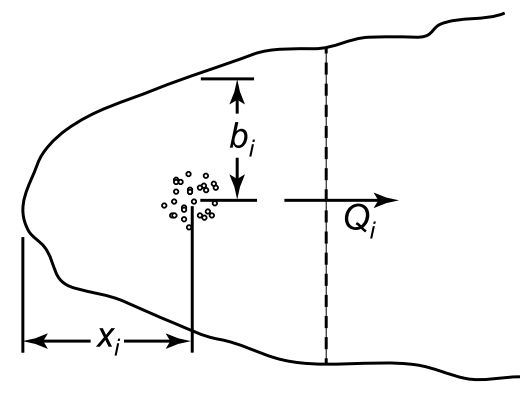

c.) Stratification Dominant in Weak Current

Figure 1. Schematic behavior of oil well blowout for (a) pure current and (b) pure stratification, and (c) stratification dominated plumes in weak current. Circles represent large oil droplets and gas bubbles, curved lines indicate the edge of the entrained seawater and dissolved hydrocarbon plume.

Table 1. Characteristics of a Multiphase Plume

\begin{tabular}{ll}
\hline \multicolumn{1}{c}{ Characteristic } & \multicolumn{1}{c}{ Equation } \\
\hline Separation height ${ }^{\mathrm{b}, \mathrm{c}}$ & $h_{s}=5.1 B_{0} /\left(U u_{s}^{2.4}\right)^{0.88}$ \\
Peel height $^{\mathrm{d}, \mathrm{e}}$ & $h_{P} /\left(B_{0} / N^{3}\right)^{1 / 4}=5.2 \exp \left[-\left(u_{s} /\left(B_{0} N\right)^{1 / 4}-1.8\right)^{2} / 10.1\right]$ \\
Trap height $^{\mathrm{d}, \mathrm{e}}$ & $\left.h_{T} /\left(B_{0} / N^{3}\right)^{1 / 4}=2.9 \exp ^{1 / 4}\left(u_{s} /\left(B_{0} N\right)^{1 / 4}-1.0\right)^{2} / 27.0\right]$ \\
Flow rate to first intrusion $^{\mathrm{d}, \mathrm{e}, \mathrm{f}}$ & $Q_{i} /\left(B_{0}^{3} / N^{5}\right)^{1 / 4}=0.9-0.38\left[u_{s} /\left(B_{0} N\right)^{1 / 4}\right]^{0.24}$ \\
Upstream penetration of first intrusion $^{\mathrm{d}, \mathrm{g}}$ & $x_{i}=0.12 Q_{i} N / U^{2}$ \\
Thickness of first intrusion $^{\mathrm{d}, \mathrm{g}}$ & $h_{i}=2.4 U / N$ \\
Width of first intrusion $^{\mathrm{d}, \mathrm{g}}$ & $b_{i}=0.32 Q_{i} N / U^{2}$ \\
Peeling fraction $^{\mathrm{d}, \mathrm{f}}$ & $f=1.0-0.048\left[u_{s} /\left(B_{0} N\right)^{1 / 4}\right]^{0.86}$ \\
\hline
\end{tabular}

\footnotetext{
${ }^{\mathrm{a}}$ See text for definition of independent variables.

${ }^{\mathrm{b}}$ For current dominated plumes.

${ }^{\mathrm{c}}$ Socolofsky and Adams [2002].

${ }^{\mathrm{d}}$ For stratification dominated plumes.

${ }^{\mathrm{e}}$ Socolofsky and Adams [2005].

${ }^{\mathrm{f} S o c o l o f s k y}$ and Adams [2003].

${ }^{\mathrm{g}}$ Akar and Jirka [1995].
} 
Table 2. Plume Characteristics for Deepwater Horizon and DeepSpill Plumes ${ }^{\mathrm{a}}$

\begin{tabular}{lcc}
\hline \multicolumn{1}{c}{ Characteristic } & Deepwater Horizon & DeepSpill \\
\hline Release depth $(\mathrm{m})$ & 1503 to 1514 & 844 \\
Net in situ oil release $\mathrm{rate}^{\mathrm{b}}\left(\mathrm{m}^{3} / \mathrm{s}\right)$ & 0.06 to 0.11 & 0.017 \\
Net in situ gas release $\mathrm{rate}^{\mathrm{b}}\left(\mathrm{m}^{3} / \mathrm{s}\right)$ & 0.04 to 0.09 & 0.007 \\
In situ density of oil $\left(\mathrm{kg} / \mathrm{m}^{3}\right)$ & 858 & 850 \\
In situ density of gas $\left(\mathrm{kg} / \mathrm{m}^{3}\right)$ & 99.2 & 40.1 \\
Net kinematic buoyancy flux of oil $^{\mathrm{b}}\left(\mathrm{m}^{4} / \mathrm{s}^{3}\right)$ & 0.09 to 0.19 & 0.029 \\
Net kinematic buoyancy flux of $\mathrm{gas}^{\mathrm{b}}\left(\mathrm{m}^{4} / \mathrm{s}^{3}\right)$ & 0.39 to 0.80 & 0.066 \\
Net total kinematic buoyancy flux $B^{\mathrm{b}}\left(\mathrm{m}^{4} / \mathrm{s}^{3}\right)$ & 0.48 to 0.98 & 0.095 \\
Gas effective droplet diameter $(\mathrm{m})$ & 0.02 & 0.02 \\
Gas slip velocity $u_{s}(\mathrm{~m} / \mathrm{s})$ & 0.21 & 0.21 \\
Non-dimensional slip velocity $U_{N}$ & 1.1 & 1.9 \\
Stratification frequency $N(1 / \mathrm{s})$ & 0.0004 to 0.0027 & 0.0015 \\
Peel height $h_{P}(\mathrm{~m})$ & 624 to 538 & 379 \\
Trap height $h_{T}(\mathrm{~m})$ & 307 to 366 & 166 \\
(First) intrusion flow rate $Q_{i}\left(\mathrm{~m}^{3} / \mathrm{s}\right)$ & 1588 to 1828 & 263 \\
Peel fraction $f$ & 0.94 to 0.95 & 0.92 \\
Typical current speed $U(\mathrm{~m} / \mathrm{s})$ & 0.078 & 0.075 \\
Critical speed $U_{c}$ above which $h_{S}<h_{P}(\mathrm{~m} / \mathrm{s})$ & 0.09 to 0.16 & 0.023 \\
\hline
\end{tabular}

${ }^{\mathrm{a}}$ Deepwater Horizon [Lehr et al., 2010] and DeepSpill Plumes [Johansen et al., 2003].

${ }^{\mathrm{b}}$ Net rates are estimated as discharge from the well head minus reported collection volume.

these may have behaved as separate plumes. After the riser was cut from the top of the blowout preventer on June 3, 2010, all oil and gas were released from a single point. Different collection schemes were also used during the spill, and collection volumes are reported by U.S. Department of Energy [2010].

[7] There also remains uncertainty in the initial behavior of the spilled fluids. There is evidence the oil atomized and that a significant fraction of gas and oil dissolved [Ryerson et al., 2011]. Yet, it is not known to what extent gas hydrates or oil emulsions were formed or how the discharge was split between the two initial leaks. The calculations below study sensitivity to these initial conditions and account for the collected oil and gas.

\subsection{Multiphase Nature of Oil and Gas Plume}

[8] Although an oil-well blowout releases fluids in several phases, the equations permit only single values for the buoyancy flux $B_{0}$ and slip (rise) velocity $u_{s}$. The buoyancy flux $B_{0}$ quantifies the combined driving force of the gas plus oil, and hence we take $B_{0}=B_{\text {gas }}+B_{\text {oil }}$. Conversely, $u_{s}$ conveys the motion of the dispersed phase relative to the continuous phase and predicts the tendency for separation and peeling. Low-density gas bubbles rise faster than even large oil droplets, so $u_{s}$ is dominated by gas. Bubbles come in a distribution of sizes, but McGinnis et al. [2004] demonstrated that bubble plume behavior can be captured using a single value of $u_{s}$ corresponding to the Sauter mean bubble diameter (diameter of equivalent sphere with same volume/ surface area ratio).

\subsection{Currents}

[9] Current speed $U$ (and direction) varies with depth and time. Below the critical speed $U_{c}$, where $h_{S}=h_{P}$, stratification dominates. Near DH, $U_{c}$ is from 0.09 to $0.16 \mathrm{~m} / \mathrm{s}$, and current speeds reported by Camilli et al. [2010] were $<0.1 \mathrm{~m} / \mathrm{s}$, suggesting that plume behavior was usually controlled by the ambient density structure, rather than by currents.

\subsection{Nonlinear Stratification}

[10] Stratification was linear in the laboratory experiments, so it could be represented in the equations (Table 1) by a constant value of $N$. To a very close approximation, potential density profiles near the DH blowout (e.g., Figure 2) varied quadratically with elevation, so $N^{2}$ increased linearly with elevation. An equivalent $N$ could be obtained by a linear fit, or by defining a linear profile with the same potential

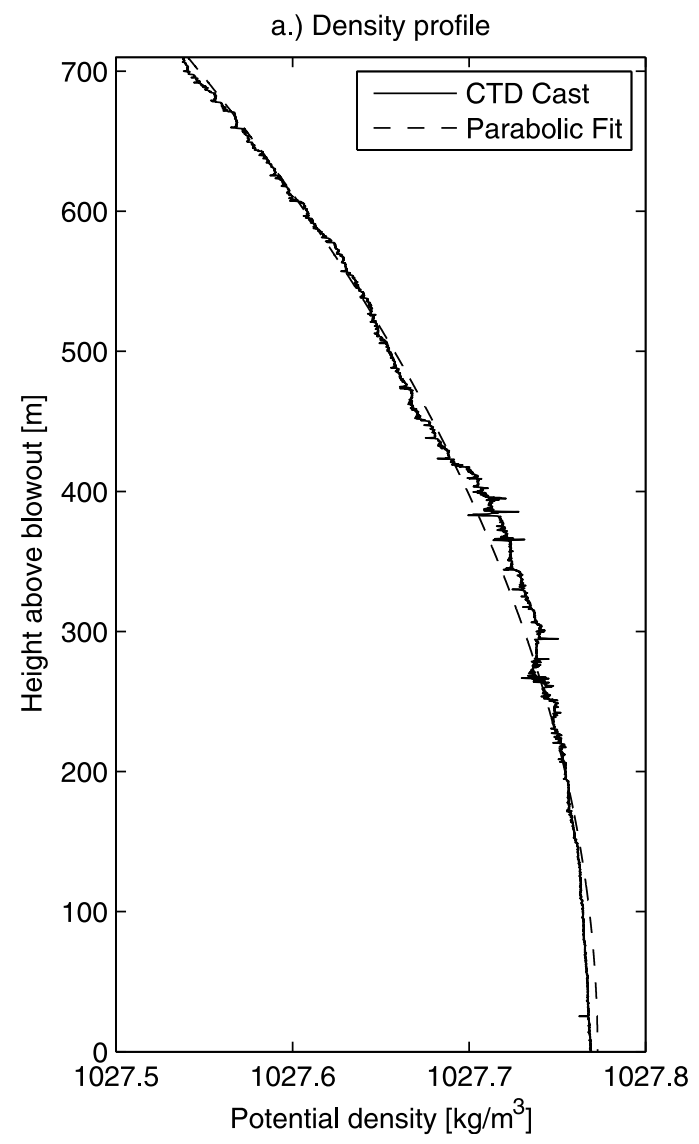

Figure 2. Density profile from the R/V Brooks McCall at Station B54 (28 43.945' N, 88 22.607' W; May 30, 2010). The solid line indicates the measured density, the dashed line is a least-squares parabolic fit given by $\hat{\rho}(z)=1027.77-$ $4.60434 \cdot 10^{-7} z^{2}$, where $z$ is meters above the blowout and $\hat{\rho}$ is the predicted density in $\mathrm{kg} / \mathrm{m}^{3}$. 
energy [Lemckert and Imberger, 1993], but for the power law density profile we choose an alternative approach.

[11] Conservation of buoyancy flux in arbitrary stratification is given by

$$
\frac{d B}{d z}=-N^{2} Q
$$

where $B(z)$ and $Q(z)$ are the local fluxes of plume buoyancy and volume [Fischer et al., 1979]. Dimensional analysis yields

$$
Q=c B_{0}^{1 / 3} z^{5 / 3}
$$

where $c$ is an empirical constant, and we represent the density profile as

$$
N^{2}=a z^{m}
$$

Substituting (2) and (3) into (1) and integrating yields

$$
B(z)-B_{0}=\frac{-c B_{0}^{1 / 3} a z^{m+8 / 3}}{m+8 / 3} .
$$

At the trap height $z=h_{T}$, the plume is approximately neutrally buoyant $\left(B\left(h_{T}\right)=0\right)$ and we solve (4) for $h_{T}$ obtaining

$$
h_{T}=\left(\frac{8}{3 c}\right)^{3 / 8} \frac{B_{0}^{1 / 4}}{N_{E}^{3 / 4}}
$$

where the equivalent $N$ is defined by

$$
N_{E}^{2}=\left(\frac{8}{3 m+8}\right) a h_{T}^{m}
$$

For a linear density profile, $m=0$, and we recover the trap height equation for constant $N$ [Fischer et al., 1979]; hence, (6) defines the equivalent buoyancy frequency in arbitrary stratification. To apply (5) and (6), we evaluate the constant $c$ such that (5) agrees with the trap height equation in Table 1, yielding

$$
c=0.156 \exp \left(\frac{\left(u_{s} /\left(B_{0} N\right)^{1 / 4}-1.0\right)^{2}}{3.38}\right),
$$

and the closed-form solution for $h_{T}$ becomes

$$
h_{T}=\left(\frac{3 m+8}{3 a c}\right)^{3 /(8+3 m)} B_{0}^{1 /(4+3 m / 2)}
$$

The dependency of $c$ on $N$ is weak and we approximate $N$ in (7) by $0.002 \mathrm{~s}^{-1}$, a typical value at $1000 \mathrm{~m}$ depth in the Gulf of Mexico. Applying (6) to (8) to the profile in Figure 2 yields $N_{E}=0.0015 \mathrm{~s}^{-1}$.

\section{Discussion}

[12] We compare our calculations against profile data collected on May 30, 2010. Oil recovery had ceased in the 5 days leading up to May 30; we assume no capture and an in situ volume flow rate ratio of oil and gas of 1:0.79 at the release. Because the ratio of release rates for each of the two leaks is unknown, we present predictions for one of the plumes, assuming $B_{0}$ ranges from $50 \%$ to $100 \%$ of the total release.

[13] Calculations for the DH plume with density profile of Figure 2 yield a peel height $h_{P}$ of 538 to $624 \mathrm{~m}$, suggesting a stratification dominated plume for current speeds less than about 0.09 to $0.16 \mathrm{~m} / \mathrm{s}$. Camilli et al. [2010] recorded current velocities averaging $0.078 \mathrm{~m} / \mathrm{s}$ at $1100 \mathrm{~m}$ depth near the $\mathrm{DH}$ blowout, suggesting the $\mathrm{DH}$ plume was stratification dominated during much, if not all, of the spill. This contrasts with the DeepSpill field experiments, against which several integral models of subsea oil and gas plumes have been calibrated [Johansen, 2003; Zheng et al., 2003]. A comparison indicates the DeepSpill experiments were dominated by horizontal velocities because they had lower flow rates, and hence less buoyancy flux $B_{0}$. Because the integral models developed through DeepSpill omit the downdraught plume structure and the possibility of multiple detrainments present in stratification dominated plumes, they may perform inadequately for plumes similar to that from $\mathrm{DH}$.

[14] Calculations for the DH plume predict a trap height $h_{T}$ of 307 to $366 \mathrm{~m}$., the fraction of entrained fluid plus dissolved and finely dispersed hydrocarbons that detrains at the first peel $f$ of 0.94 to 0.95 and an initial flow rate $Q_{i}$ for the first intrusion of 1588 to $1828 \mathrm{~m}^{3} / \mathrm{s}$ (intrusions for two independent plumes have been summed as they would flow together). Intrusion layer characteristics (Figure 1c) are evaluated for low and high current speeds with $Q_{i}=$ $1630 \mathrm{~m}^{3} / \mathrm{s}$ : at $U=0.03 \mathrm{~m} / \mathrm{s}, x_{i}$ is $335 \mathrm{~m}, h_{i}$ is $47 \mathrm{~m}$ and $b_{i}$ is $893 \mathrm{~m}$; while at $U=0.10 \mathrm{~m} / \mathrm{s}, x_{i}$ is $30 \mathrm{~m}, h_{i}$ is $156 \mathrm{~m}$, and $b_{i}$ is $80 \mathrm{~m}$. Because of buoyant spreading and collapse, the intrusion thickness decreases and its width increases with distance downstream.

[15] A vertical fluorescence profile from the same CTD cast shown in Figure 2 appears in Figure 3 along with a profile of fluorescent dye measured in a $2.4 \mathrm{~m}$ deep laboratory tank under quiescent, linearly stratified conditions having the same non-dimensional slip velocity, $U_{N}=u_{s} /(B N)^{1 / 4}$ [Socolofsky, 2001]. Comparison of the two profiles underscores the similarity between the laboratory and the field. The field profile shows a peak in the fluorescence intensity (a proxy for oil concentration) near the predicted range for $h_{T}$ (lower gray bar) and a fluorescence minimum near the prediction for $h_{P}$ (upper gray bar), just below a (much smaller) second intrusion. The smaller second intrusion suggests that little oil (field) or dye (lab) is contained in the intrusion, consistent with the peel fraction $f$ being nearly one. Hence the predictions appear well-validated.

[16] The predictive value of the empirical relationships is provided by comparing predicted values of $h_{T}$ against observed peaks in CDOM for available profiles from mid-May to mid-July 2010 (Figure 4; see also auxiliary material). ${ }^{1}$ Predicted values of $h_{T}$ based on quadratic fits of potential density versus elevation (i.e., $m=1$ ) are plotted for available CTD casts and compared with corresponding measurements of excess CDOM. Excess CDOM was determined by fitting a background profile of CDOM, and CDOM measurements that exceeded background plus four standard deviations were deemed excess. The range in excess values was typically only 5-20 units, but the plot is

${ }^{1}$ Auxiliary material data sets are available at ftp://ftp.agu.org/apend/gl/ 2011 g1047174. Other auxiliary material files are in the HTML. 
a.) R/V Brooks McCall CTD Cast

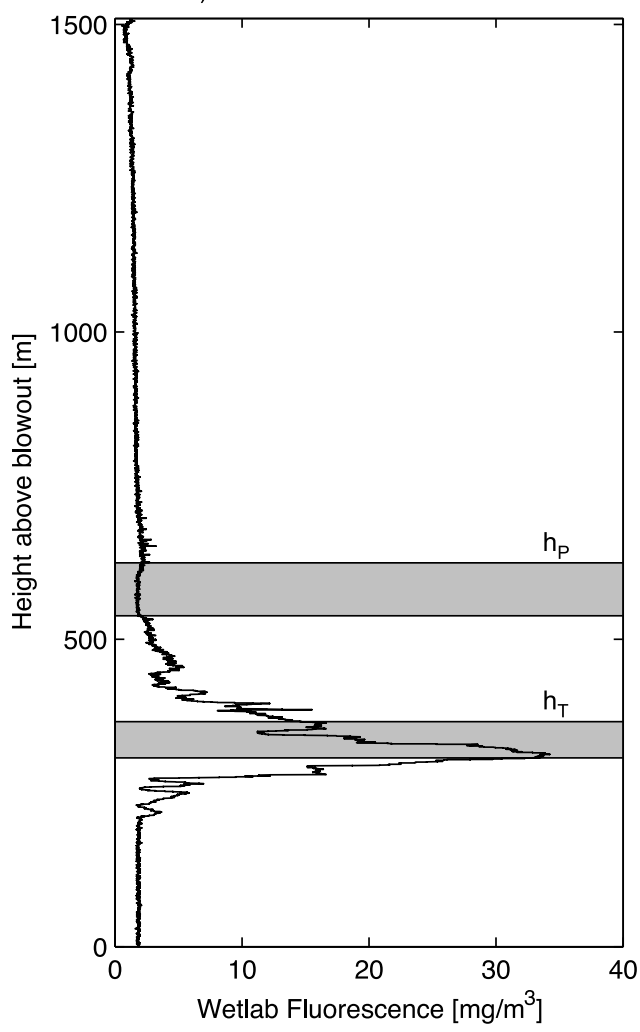

b.) Laboratory Experiment

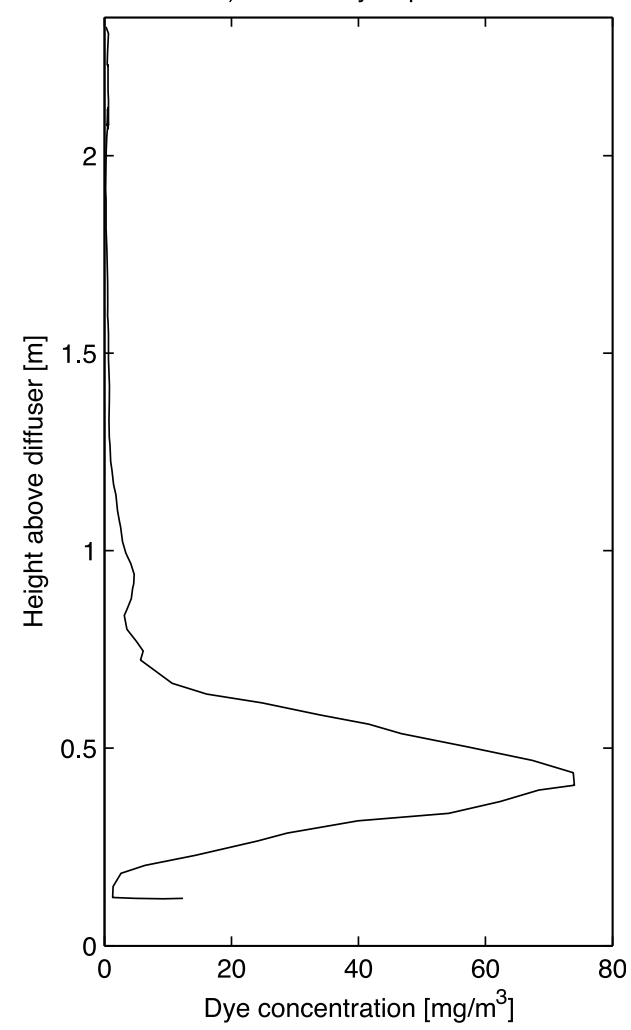

Figure 3. Profiles of fluorescence for (a) the field measurement of the R/V Brooks McCall at Station BM54 on May 30, 2010 and (b) laboratory experiment T04 reported by Socolofsky and Adams [2003, 2005]. Fluorescence in Figure 3a is related to the concentration of dissolved and dispersed liquid hydrocarbons; fluorescence in Figure $3 \mathrm{~b}$ is the concentration of Rhodamine $6 \mathrm{G}$ dye tracer injected at the laboratory diffuser as a tracer for entrained ambient water. The lower and upper gray bars in Figure 3 a are the predicted trap height $h_{T}$ and peel height $h_{P}$, respectively.

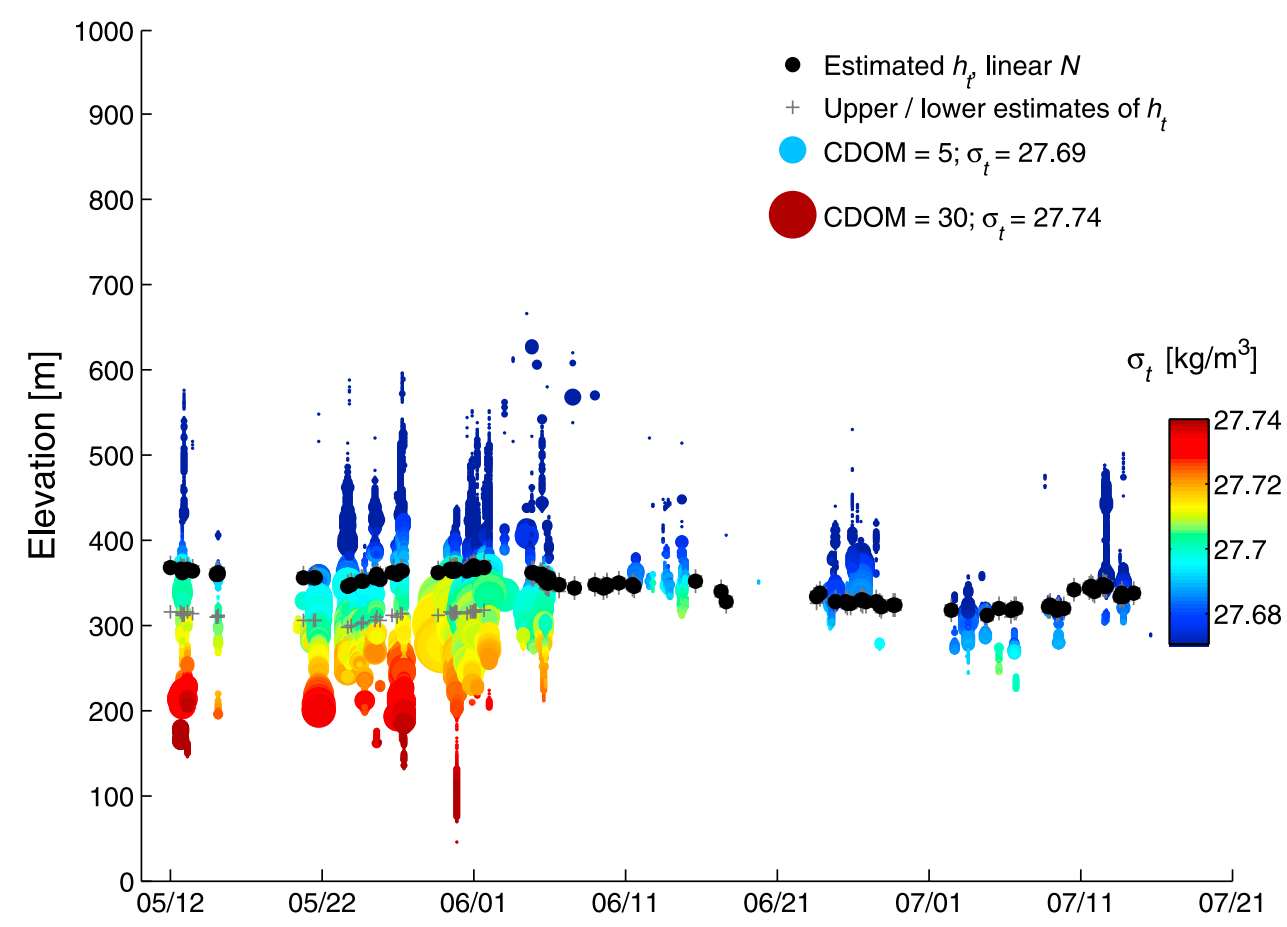

Figure 4. Time-series comparison of fluorescence measurements (colored dots) with predicted trap height $h_{T}$ (black dots; upper and lower estimates shown with gray crosses). Size of the colored dots represents the amount of "excess" fluorescence; color of the dots indicates potential density as $\sigma_{t}\left(\rho-1000 \mathrm{~kg} / \mathrm{m}^{3}\right)$. 
dominated by several profiles where excess CDOM was much larger.

[17] Acknowledgments. Funding for this project was supported by the National Science Foundation under RAPID grants CBET-1045831, CBET-1046890, and OCE-1048976, and by the U. S. Geological Survey, Coastal and Marine Geology Program. Earlier versions of the manuscript were significantly improved by suggestions from Carolyn Ruppel, Rich Signell and two anonymous reviewers.

[18] The Editor thanks two anonymous reviewers for their assistance in evaluating this paper.

\section{References}

Akar, P. J., and G. H. Jirka (1995), Buoyant spreading processes in pollutant transport and mixing part 2: Upstream spreading in weak ambient current, J. Hydraul. Res., 33, 87-100, doi:10.1080/00221689509498686.

Camilli, R., et al. (2010), Tracking hydrocarbon plume transport and biodegradation at Deepwater Horizon, Science, 330(6001), 201-204, doi: $10.1126 /$ science.1195223.

Clift, R., et al. (1978), Bubbles, Drops, and Particles, Dover, Mineola, N. Y.

Fischer, H. B., et al. (1979), Mixing in Inland and Coastal Waters, Academic, New York.

Johansen, O. (2000), DeepBlow-A Lagrangian plume model for deep water blowouts, Spill Sci. Technol. Bull., 6(2), 103-111, doi:10.1016/ S1353-2561(00)00042-6.

Johansen, O. (2003), Development and verification of deep-water blowout models, Mar. Pollut. Bull., 47(9-12), 360-368, doi:10.1016/S0025326X(03)00202-9.

Johansen, O., et al. (2003), DeepSpill-Field study of a simulated oil and gas blowout in deep water, Spill Sci. Technol. Bull., 8(5-6), 433-443, doi:10.1016/S1353-2561(02)00123-8.

Kessler, J. D., et al. (2011), A persistent oxygen anomaly reveals the fate of spilled methane in the deep Gulf of Mexico, Science, 331(6015), 312-315, doi:10.1126/science.1199697.

Lehr, B., et al. (2010), Oil Budget Calculator-Deepwater Horizon, technical documentation: a report to the National Incident Command, Coastal Response Res. Cent., Durham, N. H. [Available at http://www.crrc.unh. edu/publications/OilBudgetCalcReport_Nov2010.pdf.]
Lemckert, C. J., and J. Imberger (1993), Energetic bubble plumes in arbitrary stratification, J. Hydraul. Eng., 119(6), 680-703, doi:10.1061/ (ASCE)0733-9429(1993)119:6(680).

Masutani, S. M., and E. E. Adams (2000), Experimental study of multiphase plumes with application to deep ocean oil spills., TA\&R Proj. 377, Bur. of Ocean Energy Manage., Regul. and Enforc., Washington, D. C. [Available at http://www.boemre.gov/tarprojects/377.htm.]

McGinnis, D. F., et al. (2004), Interaction between a bubble plume and the near field in a stratified lake, Water Resour. Res., 40, W10206, doi:10.1029/2004WR003038.

National Research Council (2005), Oil Spill Dispersants: Efficacy and Effects, Natl. Acad. Press, Washington, D. C.

Ryerson, T. B., et al. (2011), Atmospheric emissions from the Deepwater Horizon spill constrain air-water partitioning, hydrocarbon fate, and leak rate, Geophys. Res. Lett., 38, L07803, doi:10.1029/2011GL046726.

Socolofsky, S. A. (2001), Laboratory experiments of multi-phase plumes in stratification and crossflow, Ph.D. dissertation thesis, 233 pp., Mass. Inst. of Technol., Cambridge.

Socolofsky, S. A., and E. E. Adams (2002), Multi-phase plumes in uniform and stratified crossflow, J. Hydraul. Res., 40(6), 661-672, doi:10.1080/ 00221680209499913.

Socolofsky, S. A., and E. E. Adams (2003), Liquid volume fluxes in stratified multiphase plumes, J. Hydraul. Eng., 129(11), 905-914, doi:10.1061/ (ASCE)0733-9429(2003)129:11(905).

Socolofsky, S. A., and E. E. Adams (2005), Role of slip velocity in the behavior of stratified multiphase plumes, J. Hydraul. Eng., 131(4), 273-282, doi:10.1061/(ASCE)0733-9429(2005)131:4(273).

U.S. Department of Energy (2010), Deepwater Horizon Response datasets, edited, Washington, D. C. [Available at http://www.energy.gov/open/ oilspilldata.htm.]

Valentine, D. L., et al. (2010), Propane respiration jump-starts microbial response to a deep oil spill, Science, 330(6001), 208-211, doi:10.1126/ science. 1196830.

Zheng, L., et al. (2003), A model for simulating deepwater oil and gas blowouts-Part I: Theory and model formulation, J. Hydraul. Res., 41(4), 339-351, doi:10.1080/00221680309499980.

E. E. Adams, Ralph M. Parsons Laboratory, Massachusetts Institute of Technology, Cambridge, MA 02139, USA.

C. R. Sherwood, U.S. Geological Survey, 384 Woods Hole Rd., Woods Hole, MA 02543, USA.

S. A. Socolofsky, Zachry Department of Civil Engineering, Texas A\&M University, College Station, TX 77843-3136, USA. (socolofs@tamu.edu) 